\title{
Language Maintenance in a Multilingual Family: Informal Heritage Language Lessons in Parent-Child Interactions
}

Mina Kheirkhah and Asta Cekaite

\author{
Linköping University Post Print
}

Tweet

N.B.: When citing this work, cite the original article.

Original Publication:

Mina Kheirkhah and Asta Cekaite, Language Maintenance in a Multilingual Family: Informal Heritage Language Lessons in Parent-Child Interactions, 2015, Multilingua - Journal of Crosscultural and Interlanguage Communiciation, (34), 3, 319-346.

http://dx.doi.org/10.1515/multi-2014-1020

Copyright: De Gruyter http://www.degruyter.com/

Postprint available at: Linköping University Electronic Press

http://urn.kb.se/resolve?urn=urn:nbn:se:liu:diva-118043 


\section{Language maintenance in a multilingual family: Informal heritage language lessons in parent-child interactions}

\section{Introduction}

Maintenance of the heritage language is a constant concern for families raising children bi/multilingually in communities where their language is a minority language. Sociolinguistic research has produced an extensive body of knowledge about the general trends that characterize language maintenance and the strong tendencies towards language shift in the second generation of immigrants (Li Wei, 1994: 11; Touminen, 1999: 60; Luykx, 2005: 1408). While research on bilingualism/multilingualism in families has suggested particular approaches to language maintenance and highlighted the interplay between wider societal processes and parental perspectives on family language policies, the family, like many domains of social life, constitutes a complex, intergenerational context for negotiating language policies and expectations regarding language use (Li Wei 2012: 1; 1994). Understanding of the processes of language maintenance/shift can be enriched by an examination of face-to-face social life and family interactions in their own right (Fishman 1991: 4). Recently, detailed investigation of family interactional practices and children's active role in reconstructing or negotiating language policies in family interactions has been highlighted as necessary and timely (Lyukx 2005; Gafaranga 2010).

The present study explores the language practices of a Persian-Kurdish family (residing in Sweden). Through these practices, heritage language maintenance and a 'one-parent onelanguage' family language strategy are realized in daily life. In this case study, we closely

examine spontaneous interactions between parents and children and explore the family members' efforts to shape children's heritage language use and learning outcomes. The focus is on the recurrent interactional practices through which parents negotiate, and enforce, a 
monolingual, heritage language 'context' (Lanza 2004) and constrain the children's language choice in parent-child interaction by targeting their 'language mixing' (Quay 2008: 6). Here, the term language mixing is used to refer to any turn/conversational contribution containing features from more than one language.

We examine the interactional trajectories and communicative dynamics that develop in these practices: parents' requests for translation (into a heritage language) made when the child produced utterances containing several languages, (Döpke 1992) and the child's uptake, that is, language choice, and compliant as well as noncompliant responses. By focusing on the multilingual family's concrete linguistic behavior, we aim to cast light on the children's role in shaping heritage language competences and use. In our view, examination of family roles, social and linguistic identities, and the social dynamics characterizing explicit parental attempts to shape children's language use can provide insights into some of the crucial conditions for family language maintenance.

The present study combines the language socialization approach (Ochs 1996) with the theoretical framework that views family language policies as socially constructed, and as including overt and implicit beliefs and norms that are manifested in and influence mundane language practices (Shohamy 2006) on the level of family interaction. According to the language socialization paradigm (Duranti, Ochs and Schieffelin 2012), children, through participation in a broad range of language practices, are socialized into and acquire the social values and expectations associated with different linguistic codes. However, socialization is not a static top-down process of intergenerational transmission of knowledge: rather, as recently emphasized by this research paradigm, it is dynamic and dialectic (Duranti et al. 2012; Cekaite 2012). Children themselves contribute to the process of forming the language policy around them, and their willing participation in adult-initiated practices cannot be assumed (Paugh 2005; Rindstedt and Aronsson 2002). Current sociolinguistic perspectives 
foreground the multi-scalar character of linguistic and interactional resources (Blommaert, 2010). Members of the community use these resources to index and negotiate dynamic, heterogeneous, linguistic and social identities, and social relations - between multilingual/monolingual speakers as well as family members (parents, children, siblings) while producing and/or contesting the local and the wider societal expectations and norms concerning appropriate and valued language choices and language use (Ochs 1996; Cekaite 2009; de Fina 2012). A detailed view at the micro-interactional level of family interactions is informative of relational and affective aspects of family language practices, which, in addition to societal values ascribed to different languages, are significant for understanding the affordances and constraints of heritage language maintenance efforts.

\section{Family language policies and children's bi-/multilingualism}

Research on bilingualism/multilingualism in families has provided a wealth of information on parents' perspectives, using interviews and questionnaires to investigate parents' language planning decisions and their conceptions of how to promote children's bilingual development (King and Fogle 2006; Piller 2001), thus connecting parental decision-making with wider societal and political policies and ideologies. Lately, several studies have highlighted parents' views on bilingualism from emotional and cognitive perspectives and the impact of these perspectives on parents' decision-making (Fogle 2013). Relatively little work, however, has been devoted to looking at the ways in which parents' and children's goals and beliefs regarding language are realized as concrete efforts to shape language use and learning outcomes (King et al. 2008; Palviainen and Boyd 2013).

Studies focusing on how bi-/multilingual families' language strategies shape young (1- to 3-year-old) children's bilingual development have highlighted the importance of social interactional context (Lanza 2004) and the quantity and quality of exposure to the heritage 
language (Chevalier 2013). For instance, in the one-parent, one-language approach, the extent to which parents attempt to promote their own language through their conversational style, that is to say, explicit or implicit interactional constraining strategies aimed at the child's use of another language, is significant in creating a so-called monolingual versus bilingual interactional context for parent-child conversations. "Implicit strategies," such as parents' repetitions and recasts of the child's utterance into parental language, are considered ambiguous, and they do not constrain the child's language choice (i.e., children do not interpret that their language choice is deemed inappropriate) (Lanza, 2004: 6). "Explicit strategies" used with young children involve requests for translation and clarification, and parents" "feigned lack of comprehension" (Lanza, 2004). It is by following explicit strategies, which unambiguously index the inappropriateness of the child's language choice, that children are more likely to use the parental language (Lanza 2004). However, studies have reported that parents may need to engage in 'insisting' in order to achieve the child's compliance with the requested language choice. Moreover, by constraining the child's language choice, parents can hinder the flow of conversation.

Ethnographically informed studies show that parents may have difficulties in following through with their intentions to use the heritage language with their children on a daily basis (Gafaranga 2010; Meyer-Pitton 2013). While parents aim to apply particular language practices, they also have to juggle the complex task of both providing input in heritage languages and managing everyday tasks. The tensions that characterize bilingual parenting also involve a conflict between the parents' wishes to raise their children bilingually and their wishes to "form emotional attachments" and to accommodate their children's choices (Fogle 2013: 86; 2012). Children's age is also an important factor in family bilingualism/language policies, though the relations between language management and children's age, that is to say, children's shifting communicative needs over time, are rarely conceptualized. Studies on 
interactional strategies mostly concern young children's (aged 1 to 3 years) bi/multilingualism, and how such language maintenance practices are realized with school-aged children is less well-charted territory, although it is suggested that "rigid adherence to language policy appears to impede communication particularly in school-aged children" (Quay 2008: 8).

\section{Children's participation in heritage language practices}

Studies adopting a dynamic perspective on language socialization have demonstrated that children's language choices and interactional practices significantly influence and shape parental language behavior (Luykx 2005; Gafaranga 2010), and that children actively contribute to language maintenance (Paugh 2005) or language shift (replacement of a language by another one), for instance, by resisting use of adults' heritage languages (Li Wei 1994; Gafaranga 2010). Gafaranga's (2010) study of intergenerational use of Kinyarwanda in an immigration context demonstrated how children, by displaying their problems in understanding the heritage language, initiated negotiations about language choice for adultchild interaction. The adults resolved the language negotiations by adopting the child's selected code, French, and established the majority language as the medium of conversation.

Children's participation in educational practices in the majority language, together with their siblings and peers, constitutes a strong language socializing factor that contributes to generational language shift (Rindstedt and Aronsson 2002; Evaldsson and Cekaite 2010). Children tend to choose language varieties that they use with their peers, and parent-child interaction becomes the crucial site for children's development of competences in the heritage language.

Some interactional studies have shown that language choice in families serves a range of interactional purposes and is locally negotiated (Ogiermann 2013). Furthermore, children can deploy various, compliant or resistant, strategies in response to parental language policies, 
using the multiple languages available to them strategically. They can align themselves with the parent or challenge parental authority (Meyer-Pitton 2013). For affective and social reasons, parents may accommodate children's language choices rather than insisting on heritage language use, by, for instance, allowing a parallel mode of interaction - children using the majority, and parents their heritage language - or adjusting to the child's choice of the majority language (Gafaranga 2010).

Thus, in the present study, we direct our attention to interactional practices through which family language policies are realized in face-to-face interactions and examine parents' requests for translation (which are viewed as successful in prompting and achieving the child's use of the heritage language, Lanza 2004). We explore interactional development and instructional/socializing potentials of these practices, and focus on the participants' language choices, as well as on the social relations and identities invoked and negotiated in parent-child interactions.

\section{Method}

\section{1. Data and participants}

The present case study is part of a larger ongoing project on language socialization patterns in five bilingual/multilingual Iranian families in Sweden (first generation adult immigrants with children born in Sweden, all families with a middle-class background and occupations). Iranians constitute a significant number of immigrants in Sweden. They are a heterogeneous group with regard to class, ethnicity (Moinian, 2007: 120) and language (e.g., Persian, Kurdish, Dari, Balochi).

The data consist of video recordings of everyday family interactions (mealtimes and sibling play; approximately five hours of video-recordings from each), ethnographic observations, and interviews with the parents and the children. ${ }^{1}$ The interviews dealt with the 
families' ethnic background, leisure activities, parents' and children's views on language, language ideologies, traditions, contact with Swedish society and speakers of their heritage languages, and children's schooling. Field notes were taken during several visits to each family (during and after the video recordings). The recordings were made by the parents themselves, using a camera on a tripod (Heath et al. 2010). Family mealtimes were chosen because they are important social events that not only give family members an opportunity to get together and share experiences, but also provide an intergenerational multiparty pragmatic context for socialization and negotiations regarding what constitutes valued language and cultural behavior (see also Blum-Kulka 1997).

The present study focuses in detail on the language practices of the only family in which the children actively used heritage languages (daily interactions in the other four families in the larger study were characterized by Persian-Swedish adult-child parallel discourse). Video recordings of family interactions were logged and transcribed (eight mealtimes and sibling play sessions). Repeated viewings, readings of transcriptions, interviews with family members, as well as observations of the family's cultural and media habits informed the analysis.

\subsection{Family language policy and practices}

The mother in the focus family is a native Persian speaker from Iran with a high level of passive knowledge of Kurdish. The father is a native Kurdish speaker, fluent in Persian. Both parents immigrated to Sweden in their adult years. They speak Swedish fluently and have middle-class occupations. Their daughters, Mona (7 years), the focus child, and Sara (11 years) started attending Swedish educational settings early in life (preschool at 1.5 years of age) and now attend a regular Swedish school. They are trilingual and use Persian, Kurdish and Swedish on a daily basis. Their Persian-speaking grandmother from Iran visits the family 
regularly. Parents and adult relatives are the children's main heritage language contacts. The children's peers (even those with a Kurdish or Persian background) use Swedish.

The parents have consciously strived to develop their children's knowledge of the heritage languages and from early on adopted a one-parent, one-language policy. The children were encouraged and requested to use Persian with Mom, and Kurdish with Dad. Family interactions were multilingual: the children predominantly adhered to the family language policy in parent-child interactions. In line with the parents' notions of child agency and sibling bonding, the siblings were allowed to choose the language of their interactions, and the girls systematically used Swedish when speaking to each other. The shared language of family interactions was Persian. The parents also noted the importance of the children knowing all three languages (Persian, Kurdish and Swedish) well, and they associated language competence with being able to use each language separately. The family, including the children, watched Persian TV shows, celebrated various (including Swedish) cultural and national events, and had positive attitudes toward their heterogeneous ethnic and linguistic identities. The children viewed themselves (in the interviews and in recorded interactions with parents) as multilingual - speakers of three languages. Sara, the older sister, was proud of her multilingual abilities and regarded them as advantageous (e.g., when discussing her future career opportunities). Mona also used all three languages and was spontaneously curious about the lexical equivalents in each of them. The girls chose not to attend the home language classes offered by the school, considering their competence in Persian and Kurdish to already exceed the level of heritage language training offered at school; their decision was supported by their parents.

The focus of the present study is on what (based on repeated viewings of recordings) have been identified as the recurrent explicit (language management) practices through which the parents negotiated and, at times, attempted to enforce the parent-child heritage language 
policy. When the children inserted a Swedish lexical item into an utterance in Persian or in Kurdish (or produced a short Swedish turn in parent-child conversation), the parents usually oriented to this as a deviation from the language norms. They asked the children to translate the problematic item into the relevant heritage language, or otherwise explicitly corrected the child by providing relevant information about the heritage language. The parents said that they did not wish to ostracize the children with too many instructions or to enforce their language policy, but that they preferred to offer corrections and instructions even in cases of child resistance. The primary target of these practices was the younger daughter, Mona, who, according to the parents, was less competent in heritage languages than her older sister. Only rarely were the children's lexical mixings targeted implicitly (i.e., by the parents moving on with the conversation but embedding the translation of the 'problematic' item into their talk).

It is important to acknowledge that explicit requests for translation are only one of the practices that are relevant to the processes of language maintenance/shift. However, they merit particular attention because they are categorized as one of the successful language constraining strategies (Lanza 2004) and were used to promote the children's use of heritage language by constraining and correcting their language choice.

\subsection{Methodological approach}

Methodologically, the present study combines the language socialization perspective involving an ethnographically informed analysis of recurrent interactional practices (Ochs 1996) with a multimodal interactional approach to human interaction and sense-making (Goodwin 2000). Fine-grained analysis of video recordings is used to examine the everyday realization of family language policies, revealed through the participants' sense-making on a turn-by-turn basis, and their use of language in conjunction with gaze, gestures and bodily actions as they were used to accomplish social actions and index particular social identities 
(Ochs 1996). These approaches were integrated into the analytical procedure because they use the sequential development of a conversation as "built-in resources for elucidating how the participants themselves are interpreting the talk in which they are engaged" (Goodwin, 1990:6) and, by combining ethnographic data, they provide a view on the dynamic instantiation of social actions and identities.

\section{Findings}

When the child, in conversations with the parents, produced an utterance containing several languages, the parents routinely requested translation of the problematic word (usually a noun, noun phrase or verb). The child's language mixing in many cases (but not necessarily) indicated a language production problem and was flagged by pauses and cut-offs (Quay 2008). The parents used routinized questions (such as, 'What is $\mathrm{x}$ called?' and announcements (albeit rarely) that articulated their alleged incomprehension of the lexical trouble source ('I didn't understand what you said'). Their utterances were produced with non-prominent intonation and monotonous voice, attesting to the routine, unmarked character of such interactional practices. They were interpreted by the child as requests for translation: what is $\mathrm{x}$ called in the language we're speaking now.

These interactional practices were multilayered in that they invoked and were constitutive of family language norms: 'use heritage language with the parent', 'family's multiple languages have to be kept separate in utterances'; 'children have to know, and to learn, the heritage language'. The parents invoked and negotiated a monolingual, heritage language context of interaction (Lanza 2004) and displayed their identities as competent speakers of the heritage language, while pointing out the child's normative deviation from the family language policy. The child was simultaneously positioned as insufficiently competent in Kurdish or Persian. On the local interactional level, the heritage language competences were 
constituted as valued and desirable when the parents demanded, encouraged and commended their use.

The child's responses entailed a broad phenomenology of interactional moves. Mona recurrently produced the translation; however, rather frequently, she did not immediately engage in the requested action. The non-forthcoming responses can be characterized in relation to the child's verbal and embodied affective and epistemic stances (Du Bois 2007; Goodwin, Cekaite \& Goodwin 2012), and the types of reason-giving offered by the child. For instance, they entailed accounts that topicalized Mona's lack of heritage language knowledge. The child displayed negative affective stances, demonstrating her resistance and unwillingness to contribute to the requests for translation. The child's non-forthcoming 'translation' moves also entailed her self-definition as someone who does not understand, speak, or wish to learn the language in question, and as someone who does not wish to participate in the informal instructional exchanges. These moves were indexical of identities in this case as unknowledgeable or/and resistant child - that in their turn contributed to the extended trajectory (or termination) of parent-initiated language instruction (e.g., Cekaite 2012).

In the following, we examine the interactional and instructional features of the sequences, introducing requests for translation, and the identities displayed and negotiated by the family members. We outline the child's different types of responses, as well as the types of parental uptake, including their instructional assessments, and the insistent moves that enforced the heritage language policy when the child did not produce a relevant contribution.

\subsection{Requests for translation as an educational Initiation-Response-Feedback (IRF) sequence}

By initiating a request for translation, the parents changed the focus of interaction from the exchange of meaning to language form. They pointed out the child's inappropriate language choice, and foregrounded the importance of multilingual repertoires and competences in 
heritage languages. Parental requests for translation resembled instructional IRF (initiationresponse-feedback) sequences, which are characteristic of formal teaching activities, including language lessons (Seedhouse 2004). The 'experts' (teachers, or here, the parents) initiate an examination of the respondent's knowledge by asking a known information question, which requires that the child publicly demonstrate her knowledge. In addition, such conversational insertion sequences (e.g., Jefferson 1986) interrupt the flow of the ongoing conversation.

The first extract (Ex.1) demonstrates the child's compliant responses to the parents' request for translation. During the dinner, Mona, Mom, and Grandmother talk about Mona singing Azeri songs with Grandmother. The main language of their exchange is Persian. (Simplified transcription conventions: vet inte: talk in Swedish, afarin: talk in Persian, lowbia: talk in Kurdish; okay bean: translation to English from Swedish, Persian or Kurdish).

\section{Ex. 1 Participants: Mom, Mona, Grandmother}

1 Mom kei bud mixund-i:? pariruz. parišab. when be.PST.3SG sing.PST-2SG day before yesterday evening before yesterday when was it you were singing? the day before yesterday, the evening before yesterday

((unrelated lines omitted))

2 Mona hamin: ${ }^{2}$ sönd- eh söndag. ((looks at mom then starts buttering bread)) this sund- eh Sunday Well Sund- Sunday. (.4) ((Mom looks at Mona))

4 Mom-> söndag yarni či:. ((monotonous voice)) Sunday meaning what What is Sunday called?

5 Mona ((stops buttering bread $))^{\circ} . \mathrm{pt} \mathrm{uh}^{\circ} *(.5)$

6 Mona-> ${ }^{\circ}$ yekšzmbe $e^{\circ}$.((continues buttering bread)) Sunday.

8 Mom yani ČI:? ((monotonous voice)) 
9 Mona YEKšsmbe. SUNday.

11 Mom afarin.

Well done.

12

13 Mona

\begin{tabular}{|c|c|c|c|c|c|}
\hline & mann & fek-kard-amm & yekšambe & hasmin måndag & s. $\quad($ smiling, to Mom \\
\hline mom & & think-PST-1SG & Sunday & this Monday & be.PRS.3SG \\
\hline
\end{tabular}

14 Mom

.$p t * *$ måndag či miše: (.) $\quad$ be farsi?
no Monday what become.PRS.3SG in Persian
No what is Monday called in Persian?

15 Mona (1.6) (('thinking face'))

16 Mona došzmbe:, sesaambe ${ }^{\circ} \mathrm{xxx}^{\circ}$

Monday. Tuesday $x x x$

17

((Mom and GM talk to Sara who enters the kitchen;))

* Interjection .pt and a sigh 'uh' display irritation.

** pt is used here as a negation (in Persian).

In her response to Mom's question (in Persian) about the day when she was singing, Mona starts out in Persian 'hammin' but then switches to Swedish 'sönd-'. Perturbations in her talk (cut off and filled pause) can be seen to flag a language production problem (line 2).

It is this language mixing that Mom targets in her request for translation, asking in Persian 'what is Sunday called?'. She specifies the problem source, the Swedish word 'söndag', and indexes the normative preference to preserve Persian as the monolingual context of their conversation. Mona complies with the request and, after some hesitation sounds and a sigh, produces the requested word in Persian 'yekšambe' (line 6). Mom, who is simultaneously engaged in mealtime preparations, probably does not hear her sotto voce reply; she recycles her upgraded, louder and insistent, request (line 8) and then positively assesses Mona's response ('well done', line 11). Mom's and daughter's interactional moves resemble the 
educational IRF sequence: the parent initiates a known information question requiring that the child publicly demonstrate her knowledge. Her feedback ('well done') evaluates the correctness of the child's response.

Here we also see the pervasiveness of the language instructional features in parent-child interactions. When Mona, smiling, issues a meta-comment about her language difficulties, that is, she thought that 'Sunday' in Persian is Monday ('måndag') in Swedish (line 13), Mom quickly responds to Mona's self-disclosure by rejecting her 'language hypothesis' and issues yet another request for translation (line 14). After a considerable pause and 'thinking face', Mona produces a requested noun ('došmmbe') in a mnemonic sequence of weekdays (that resembles a rote-learning practice used in primary educational settings).

As demonstrated, the child's lexical mixing occasions the parent's request of translation and an informal language lesson that is initiated as a language maintenance strategy. However, similarly to the classroom IRF structures used to examine students' knowledge, it invokes the participants' asymmetric roles, where the adult takes on, and in this case, is ascribed by the child the identity of being the knowledgeable one, the authority who is in a position to evaluate the child's heritage language knowledge.

\subsection{Language instruction and the child's non-forthcoming responses}

5.2.1. Expanded language instruction. One recurrent type of interactional practice entailed the child's non-forthcoming responses/translations. The child displayed or claimed her partial lack of competence by, for instance, answering in the wrong language, delaying a response, producing epistemic disclaimers and self-definitions as someone who does not know the answer in the heritage language: 'I don't remember'; 'I don't know'; 'I can't say it in Kurdish'. Such responses constituted affordances for the parent to initiate an expanded instructional exchange: to provide linguistic information, for example, a lexical model, and ask the child to rehearse a problematic lexical item or items. 
In Ex. 2, we see a request for translation and a full-fledged language instruction after the child's translation is not forthcoming. Here, Mona and Mom are preparing breakfast. Throughout this episode, Mona is selecting good grapes from a bunch of grapes. She tells Mom that the grapes are all rotten. She starts her utterance in Persian (Mom's language), but then uses the Swedish word 'rotten' ('rutten', line 1).

Ex. 2 Participants: Mona, Mom (Mom is engaged in various chores)

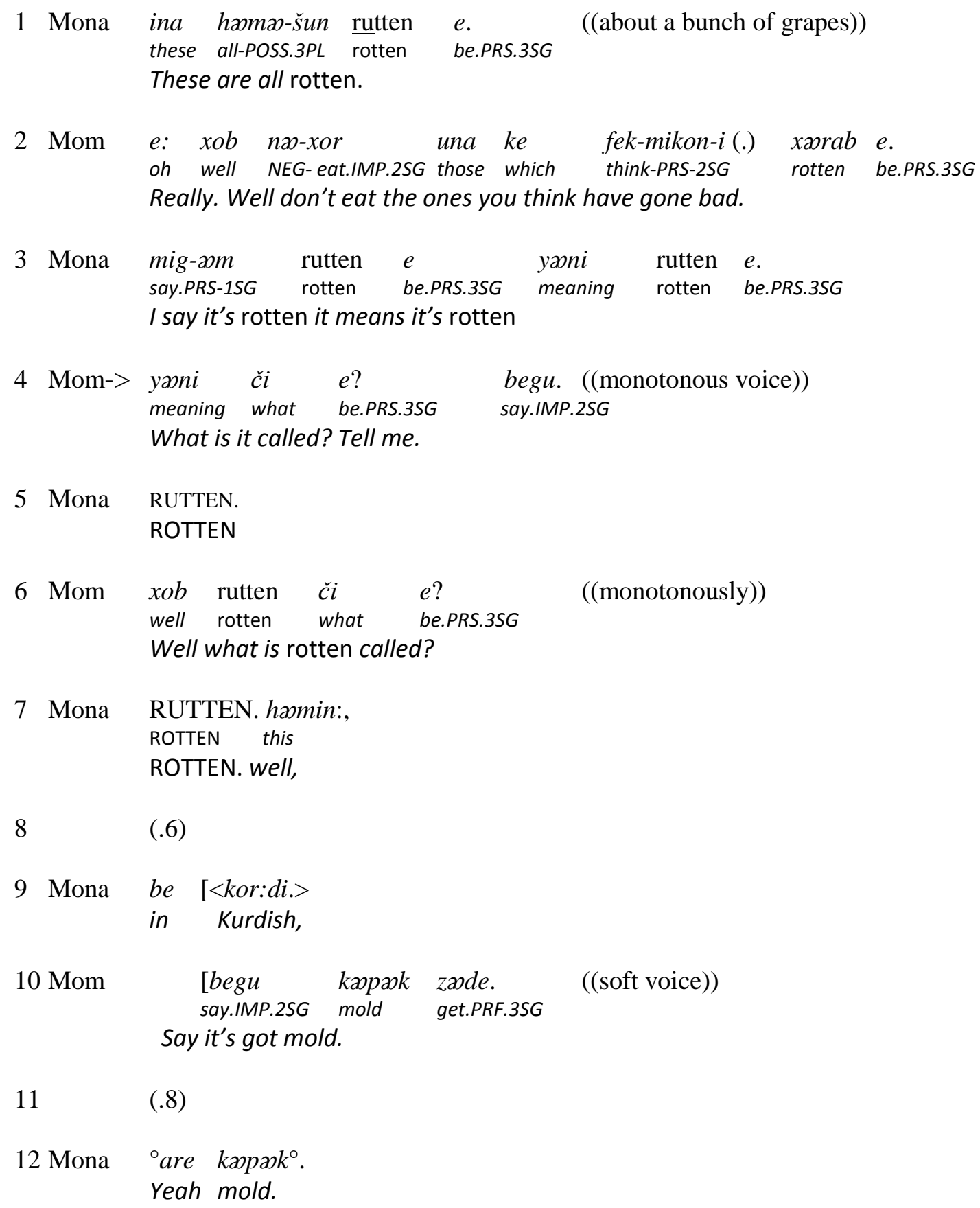




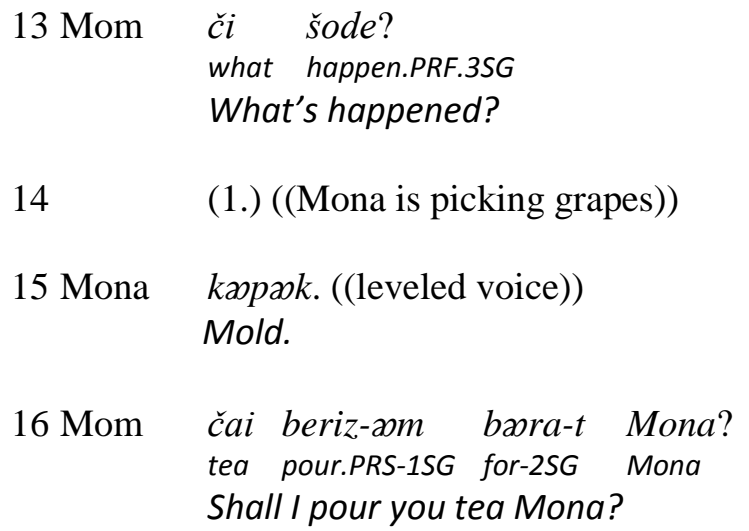

Mom and Mona's conversation is in Persian, but Mona repeatedly uses the Swedish rotten in her utterances (lines $1 ; 3$ ). The heritage language instruction evolves spontaneously as mother and daughter are engrossed in their morning chores. Initially, Mom responds to the propositional content of Mona's utterance, telling her not to select rotten grapes; instead of initiating a request for translation, Mom simply incorporates the Persian equivalent into her utterance (line 2). However, upon Mona's repeated use of the Swedish word, Mom requests a translation, 'what is it called? Tell me' (line 4). In response, Mona produces the Swedish item 'rutten' ('rotten') again in a louder voice and switches to Persian (probably engaging in a word search) (line 7). ${ }^{3}$ Mom then initiates an instructional sequence, modeling the word in Persian, and demanding that Mona repeat it: 'say it's got mold' (line 10).

Mona's sotto voce repetition of the problematic lexical item (line 12) probably escapes Mom's attention, and she issues a repeated, insistent request: 'what's happened?'. She once again aligns with Mom's instructional activity (adopting the identity of a compliant heritage language learner) and repeats 'mold' in Persian (line 15). Upon the child's repetition of the lexical item in the requested language, the instructional sequence is complete, and Mom shifts to another activity (breakfast preparation).

The parents also used other interactional formats to engage the child in the heritage language instruction: They feigned a lack of understanding ('I don't understand') (e.g., 
Lanza, 2004), or simply asked that Mona repeat the correct item. The parents' insistent efforts to secure or enforce the child's participation in informal heritage language instruction actualized the hierarchical parent-child positions regarding their identities as competent heritage language speakers versus a learner (somebody who needs to rehearse, and be informed about the heritage language). These insistent language maintenance practices served as a social site for the construction and negotiation of the child-parent relationship, here characterized by the child's playful or serious resistance.

In Ex. 3, Mona asks Dad to serve her more food. Their conversation progresses in Kurdish (Dad's language), until Mona asks Dad for some more beans, using Kurdish initially, but then switching to Swedish, 'kəmi bönor' (line 6). Mona continues her request for more food in Swedish 'bönor. Kan vi ta e-'/ 'beans. Can we take e-' (line 8).

\section{Ex. 3 Participants: Mona, Dad}

1 Mona BABA: xxx low-čət-gəl-æx berežn. ((lifts her plate towards Dad)) dad of that-thing-PL-DEF pour.IMP

DAD xxx give me some of those.

2 Dad bərəž-mæ? ((points at stew))

pour.PRS-1SG

Shall I serve?

3 Mona are.

Yeah

$4 \quad$ (.9) ((Dad fills spoon with meatballs))

5 Dad čən dænə baš-ə. čwar [dænə? ((serving meatballs))

how piece be-3Sg four piece

How many do you want, four?

6 Mona

[e:: kəmi bönor.

e a few beans

A few beans.

7 Dad (.4) 'ka:y.

8 Mona bönor. >kan vi ta $\mathrm{e}-<$

beans can 2PL take e-

beans. can we take e- 
9 Dad-> aw-ə eiž-ən pe lowbia.((Dad fills spoon with beans and lifts spoon, looking at Mona))

that-DEF say.PRS.3PL to bean

These are called beans.

10 Mona-> a bönor. ((brings her plate closer, smiling))

Yeah beans.

$11 \quad(.6)(($ Mona smiles $))$

12 Dad bež-ə lowbia. ((holds spoon with beans over Mona’s plate))

say.IMP-2SG beans

Say beans.

13 (.4) ((Dad looks at Mona, Mona's heavy plate is shaking))

14 Mona okay. lowbia. ((smiling))

Okay beans.

$15 \mathrm{Dad} \quad(($ serves beans))

16 Mona A:H ( ${ }^{\circ}$ toze $\quad$ low-a $\left.{ }^{\circ}\right)(($ playfully sticks her tongue out $))$

ah a little that-DEF

$\mathrm{AH}$ a little of that.

17 Dad lowbia-y sur.

bean-EZ red

red beans

Mona's use of the Swedish noun 'bönor' is identified by Dad as a gap in her Kurdish language knowledge, and he picks up this lexical element as problematic (line 9). Dad issues an expanded instruction about a Kurdish equivalent, 'lowbia', and re-establishes the monolingual context by switching to Kurdish (enacting the family language policy that the heritage language is used in parent-child conversations). The instructional nature of Dad's talk is highlighted by his emphatic pronunciation of the problematic item (line 9). He also models the relevant answer and demands that Mona repeat the Kurdish noun.

Smiling, Mona repeats the problematic item, but in Swedish (line 10). She confirms Dad's instruction as a relevant piece of information (minimal acknowledgement token 'a'/'yeah'), but displays her playful resistance to participate in the parent-initiated instructional exchange, a Kurdish language 'lesson'. While she responds with a smile to the propositional content of Dad's utterance, she disregards his choice of language by switching to Swedish (see Cromdal 
2004; Bani-Shoraka 2008) and engages in agentive negotiations of linguistic and social identities.

However, Dad, in a playful tone, demands that Mona repeat the problematic Kurdish word ('say beans', line 12), while he refrains from carrying through with Mona's prior request (in Swedish) for more beans. The command 'say beans' bears a clear resemblance with language instructional practices used in formal and informal/family settings (e.g. Ochs 1988) that both model the relevant lexical element, and require that the child repeat and rehearse the word (line 12). Dad's directive is overlaid with an embodied action (teasing Mona, he stops serving her), and it interrupts the ongoing mealtime activity.

The plate is getting heavy for Mona and she complies with Dad's directive: smilingly, she repeats the problematic item 'beans' in Kurdish (line 14) (with a turn-initial agreement token 'okay' framing her turn as an explicit act of giving in). Mona's repetition of the Kurdish word constitutes a necessary condition for Dad to finally serve her (line 15). Dad continues the instructional exchange and provides yet another expanded instruction about the problematic item in Kurdish, 'red beans' (line 17).

This playful Kurdish language instructional exchange provides an example of a recurrent parent-initiated 'language lesson' that emerges in cases when the child does not produce the lexical item. The parent provides linguistic information and models the language for the child, soliciting the child's active participation in heritage language learning/rehearsing practices. This playful exchange also exemplifies the 'give-and-take' of family life (Schieffellin 1990), where Dad and Mona display relations of mutual dependency and affection, lighthearted coercion and resistance, playing with their responsibilities and obligations, while also invoking asymmetrical relations and language competencies.

5.3 The child's affectively upgraded refusals and parents' responses 
5.3.1 Accommodating the child's resistance: Terminating the informal language instruction. Requests for translation were also a risky 'business' that could threaten the social ambience of family interactions. At times, they occasioned the child's affectively upgraded refusals, and extended disagreement sequences between the parents and the child. The child's noncompliant responses entailed affectively upgraded interactional moves that displayed her negative, embodied, affective stances (being angry, irritated, resigned, e.g., 'I don't feel like saying it'). She topicalized her outright objections and stated her lack of competence in the heritage language ('no'; 'I DON'T KNOW'; 'I can't speak Persian I said'; 'I don't know Kurdish well'), demonstrating her reluctance to participate in these informal language learning practices. Mona declared that she was unwilling to use and/or learn the requested language, in this way contesting the parents' categorization of her as someone who is becoming multilingual and who needs to participate in language instruction. Parental insistent moves were numerous, but the resolution of affectively upgraded sequences rarely involved extended language instruction.

In Ex. 4 Mom asks Mona about her schoolwork, but she names a wrong day ('today') and Mona gets irritated, telling Mom that she is wrong about which day she presented her homework at school ('Tuesday'). Mona uses both Persian and Swedish, and Mom targets this lexical mixing (line 7).

Ex. 4 Participants: Mona, Mom, Dad, Sara, Grandmother

1 Mom Mona emruz (1.8) tu mandrese (.6) tammrina-t-o anjam-dad-i:? xund-i:?

Mona today at school assignmens-POSS.2SG-ACC do-PST-2SG read.PST-2SG

Mona did you do your assignments today at school? Did you read them

bara xanum-etun?

for teacher-POSS.2PL

to your teacher?

2 Mona (.7) ((pours syrup))

3 Mom hm?

4 Mona ((nods)) 
$\begin{array}{lll}5 \text { Mom } & \check{c} i \quad \text { xund-i? } \\ & \text { what read.PST-2SG } \\ & \text { What did you read? }\end{array}$

$6 \quad(.6)$

7 Mona MAMAN MAEN EMRUZ NE-MIXUN-AEM. TI:SDA:. ((angrily, hits table)) mom I today NEG-read.PRS.1SG Tuesday MOM I DON'T READ TODAY. TUESDAY

8 Mom-> tisdag miš-e či? ((monotonous voice))

Tuesday become-PRS.3SG what

What is Tuesday called?

9

$10 \mathrm{Dad} \quad$ diruz bud. $\quad\left[{ }^{\circ}\right.$ diruz $\quad b u d .{ }^{\circ}$ ((to Mom))

yesterday be.PST.3SG yesterday be.PST.3SG

It was yesterday. It was yesterday.

11 Mona->

[mann hal nas-dar-aom beg-anm.(('sullen' voice, pours syrup)) I mood NEG-have.PRS-1SG say-1SG

I don't feel like saying it.

12 Mom $\underline{e}$.

oh

13 Adults: ((laughter))

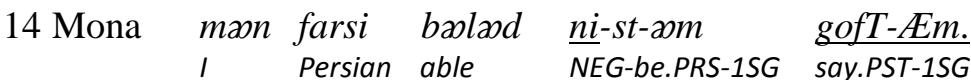

I don't know Persian I said.

15

16 Mom uhu.

aha

17 Dad Mona zonar dus-dar-e vase-in-e lopa-šs $\quad$ germez šode ((to GM then to Mona))

Mona pomegranate like-PRS-3SG for-this-be.PRS.3SG cheeks-POSS.3SG red become.PRF Mona likes pomegranate, that's why her cheeks have become red.

18

(2.)

19 Mona mən həzz-nəm $\mathbf{x x x}$ ((turns to Dad))

I like-NEG.PRS.1SG

I don't like xxx.

In response to Mom's question, Mona shouts in Persian 'MOM I DON'T READ TODAY', then 'Tuesday' in Swedish (line 7). Mona has reported her homework to her teacher some 
days earlier, and she strongly objects to Mom's mistake. However, instead of responding to the propositional content of Mona's turn, Mom targets Mona's language mixing and asks for translation 'what is Tuesday called?' (line 8). She uses a monotonous, 'matter-of-fact' voice (see also Ex.1,2) that contrasts with Mona's affectively charged turn. However, instead of the requested translation, Mona starts pouring syrup again, and articulates an affectively valorized refusal 'I don't feel like saying it' (line 11).

The adults, through shared laughter, take a humorous, rather than serious stance on Mona's objection (line 13), and Mona upgrades her refusal by negating and contesting her competence in the heritage language, 'I don't know Persian I said' (line 14). Interestingly, she uses Persian, indicating her alignment with the family language policy on the level of language choice, even as she refuses to participate in the informal language lesson. While the child's self-disclosures about her lack of knowledge/competence in the heritage language (Ex. 1; 3) provided interactional affordances for the parents to pursue and engage the child in language instruction, Mona's upgraded negative affective stance generates an affectively charged situation, and Dad terminates this topic. He also shifts the keying of the conversation (line 17). (Smiling, he turns to and tells Grandmother 'Mona likes pomegranate that's why her cheeks have become red'; probably referring to Mona's angry accounts in lines 11 and 14). Moreover, Mona shifts the addressee and the language, clearly marking her unavailability (and disalignment) with Mom: she turns to and addresses Dad in Kurdish (although Dad uses Persian to address Grandmother in line 17).

As demonstrated in Ex. 4, the child's resistance in relation to the informal heritage language instruction was displayed and negotiated as affectively valorized refusals: the parents and the child exchanged oppositional turns until the topic or the keying of the exchange had changed. For the most part, the child, at least locally, won these negotiations by withdrawing from the conversational exchange, and the parents terminated the requests for 
translation, accommodating the child's resistance and working to restore the social ambience of family interactions.

\subsubsection{Parents' insistent moves: Invoking meta-level language policy}

In response to the child's refusals, the parents produced numerous insistent moves in an attempt to recruit the child's compliant participation. Refusals generated situations in which we can witness (frequent) metalinguistic comments and meta-level family language policy: the parents explicitly invoked the family language policies to support their insistent moves and stated the child's obligation to learn the heritage languages.

In Ex. 5, Dad, Mona and Sara talk about Christmas. Mona starts an utterance in Persian but switches to Swedish ('I knew every day twenty fourth xx', line 1).

\section{Ex. 5 Participants: Mona, Dad, Mom, Sara, Grandmother}

1 Mona e: midun-es-amm varje dag ${ }^{\circ}$ tjugo fjärde $\left[\mathrm{xx}^{\circ}\right.$

$e$ know-PST-1SG every day twenty fourth $\mathrm{xx}$

e I knew every day twenty fourth $\mathrm{xx}$

2 Dad ->

3

4 Mona

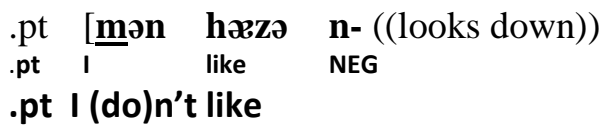

$5 \mathrm{Dad}$

[rože.

day

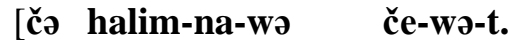

what understand.1SG-NEG what-say.PST.2SG

What? I don't understand what you said.

6 Mona-> MəN Nə-TAN-OM BE KURDI BEž-æm. mən kurdi ${ }^{\circ}$ xas na-zan-əm ${ }^{\circ}$ I NEG-can.PRS-1SG in Kurdish say.PRS-1SG I I can't say in Kurdish. I don't know Kurdish well.

$7 \mathrm{Dad}$

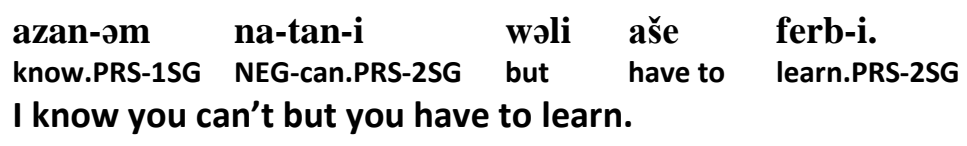

8 Mona näa

no

(3.) ((Mona eats)) 
$10 \mathrm{Dad}$

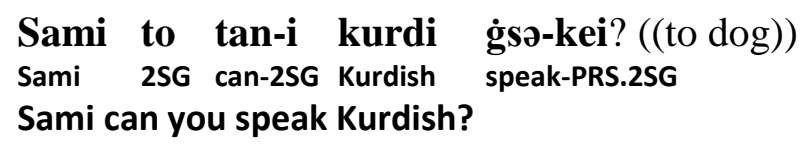

$12 \mathrm{Dad}$

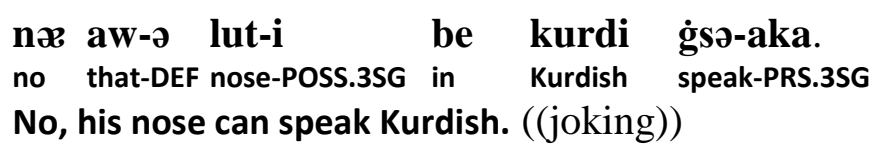

Dad interrupts Mona's turn, using Kurdish to bring attention to his alleged problem in understanding 'What? I don't understand what you said' (line 2). Multiple languages Persian, Swedish and Kurdish - are at play: Dad targets a Swedish item, while he also shifts to Kurdish from the main language of this encounter, Persian. Mona responds with a negatively valorized objection, a sigh and a statement 'I like not', interpretable as 'I don't like' (in Kurdish negation occupies a post-verb position in compound verbs). Thus, while in interactions with young bilingual children, parents' claims of their (feigned) problems of understanding facilitate the child's heritage language production (e.g., Lanza, 2004), Mona does not take Dad's statement at face value. Rather, she interprets it as a rhetorical device that he uses to initiate language instruction. Dad points out the trouble source 'day' (partially modeling a correct response, see Ex. 3), but Mona refuses to engage in this informal examination and instruction by claiming her lack of Kurdish language knowledge: 'I can't say in Kurdish. I don't know Kurdish well' (line 6). Paradoxically, she aligns with the family language policy by adjusting to Dad's language choice. While Dad acknowledges the daughter's difficulties ('I know you can't'), he also formulates a non-negotiable metastatement about the family language policy, 'you have to learn' (line 7), to which Mona responds with a blunt refusal 'no' (line 8), this time upgraded through her choice of Swedish. By engaging in eating, she visibly shifts the participation framework and marks her withdrawal from the conversation with Dad. Her refusals are multifaceted: they target and object to the family language policy; in addition, Mona can be seen as objecting to being 
positioned as a language learner, who has to participate in language instruction instead of being allowed to use her already available language resources (e.g., Swedish).

Following the escalating confrontation, Dad terminates the instructional exchange and transforms the keying of the interaction from serious to playful/non-serious (Goffman 1974) (he addresses the dog about the same topic, i.e., learning Kurdish). In all, the disagreement is terminated without any consensus or compromise (both of which are face-threatening; see Vuchinich 1990) regarding the family language policy, namely, the responsibility of the child to learn the heritage language. Locally, however, Mona's resistance allows her to avoid participation in the language instruction and forces Dad to accommodate the child by abandoning the instructional focus on the heritage language.

\section{Concluding discussion}

The present case study explored how family language policies are instantiated and negotiated in everyday parent-child interactions, and revealed a multifaceted picture of language socialization and parental language maintenance efforts in a multilingual family. As demonstrated, the intergenerational family mealtime conversations were exploited in making heritage language maintenance, and the children's multilingual competencies, the explicit focus of parent-child interactions (Ex. 1-5). The parents used various resources: requests for translation as well as displays of (feigned) non-understanding when targeting the child's language mixing. They suspended the ongoing conversational activity and shifted the focus from interactional concerns and meaning-making to language choice and language form. The parents constrained the child's language choice, consistently attempting to enforce a monolingual interactional context/monolingual exchange (potentially beneficial for heritage language maintenance). The multiple languages used in the family added to the complexity of 
heritage language maintenance efforts in terms of learning tasks, posed for the child, and her conversational participation in the multiparty, linguistically diverse participant constellations.

The parents' requests for translation resembled formal language teaching practices (e.g., IRF discursive structure): the parents pointed out a specific lexical problem/trouble source and requested that the child correct it, that is, translate the problematic lexical item into the heritage language. They also modeled responses for the child, provided (expanded) instruction and insisted on the child's active participation and rehearsal of the target lexical items.

These practices were also instrumental in the parents' efforts to resolve what can be regarded as one of the crucial dilemmas of child heritage language development and intergenerational heritage language maintenance: the need to continuously expand the child's communicative repertoires so as to cover an increasing range of conversational topics, and to use language in various encounters. These topics inevitably become more elaborate as the child grows older and engages with more sophisticated and complex aspects of social life.

While these strategies, as observed in studies on young children (Döpke 1992; Lanza 2004), are relevant and efficient in constraining the child's language choice (and, in doing so, are beneficial to the child's heritage language development), their use, as demonstrated here, was also associated with some problematic features. These resources were potentially 'threatening' to the social ambience of family interactions: not only did they interrupt the child's conversational contribution and conversational flow, but they also initiated informal language instructions, that exposed and criticized the child's language choice, and directed the participants' attention to what the parents had identified as a flaw in the child's utterance. The parents' claims not to understand were not taken at face value; rather, such interactional moves were interpreted as resources for initiating language instruction. The instructional exchanges were characterized by an asymmetrical role distribution: the parents positioned 
themselves as 'experts' and exercised their authority to examine and correct the child's heritage language knowledge, insisting on the child's active participation in spontaneous language instructional exchanges (Ex. 1-3).

The child's resistance and blatant refusals to participate in these practices were recurrent, and when the refusals were affectively aggravated, the parents accommodated the child by suspending and terminating the language instruction (Ex. 4-6) (see Gafaranga 2010; Fogle 2012). The child's refusals were multilayered: they targeted the family's language policy and can be seen as responsive to wider societal ideologies, namely, the normative preference for Swedish. Her refusals can also be linked to her being positioned in family (micro-level) interactions as a language learner, who has to participate in language instruction instead of being allowed to use her easily available language resources (e.g., Swedish). The development of the informal language instruction was thus dependent on the child's willingness to collaborate and participate and to adopt the identity of a 'less knowledgeable'/heritage language 'learner'.

In all, while research on language maintenance/bilingualism in families has provided a substantial body of findings on parents' perspectives, and on early bilingualism, the present study shows that it is fruitful to bridge the gap between these approaches by examining the interactional realization of language policies in families with older children. Multiple factors - societal language ideologies, policies, as well as daily interactional practices in communities, families, and institutions - affect children's heritage language development. Research examining linguistic phenomena (like those discussed here) from a multimodal interactional perspective demonstrates that focusing on the family members', parents', and children's concrete linguistic behavior, and on the way they negotiate the use of different language varieties, reveals some of the significant factors that shape the implementation of family language policies. Video recordings of family interactions allow researchers to 
uncover the affective tenor of encounters, shifts, and re-organizations of participation frameworks, thus providing a rich ground for the investigation of how language maintenance efforts evolve and are transformed in family interactions.

The family's language practices and the child's resistance can be seen in light of wider societal processes and language ideologies, that is, the normative primacy of the majority language (Blommaert, 2010). Importantly, a significant dimension that is related to heritage language maintenance is also, as demonstrated in the present study, inextricably linked to the emotional and relational features of family life, and the multifaceted - linguistic, and social identity work of family members. The present case study has also wider implications for research on language maintenance and family language policies, as it points out the importance of directing attention to the child's contributions: the child as a willing or resistant participant in the family's language practices. If research is to inform language maintenance efforts, it may benefit from an understanding of the social interactional processes through which family language policies are realized or contested in face-to-face interaction. The detailed ethnographically informed studies can contribute to the conceptualization of language maintenance (and children's heritage language socialization) as a dynamic and dialectic process that is shaped, negotiated, or resisted by both the children and the adults.

\section{Footnotes}

\footnotetext{
${ }^{1}$ The data collection in families and in the primary school has followed the Swedish Research Council's ethical directions for collecting and handling data. Names and other identifiers have been anonymized. ${ }^{2}$ Mona uses ‘hæmin' frequently. Therefore, it comes in different meanings, both as a pronoun and a discourse
marker.
}

${ }^{3}$ She may not know which language (Persian or Swedish) 'rutten' belongs to.

\section{Transcription key}

Talk has been transcribed by using conventions developed by G. Jefferson. 
(.5) pauses in tenths of a second

(.) micropause, i.e., shorter than (0.2)

$=\quad$ latching between utterances

[ overlapping talk

- $\quad$ denotes cut-off

: $\quad$ prolonged syllable

. denotes falling terminal intonation

? denotes rising terminal intonation

$>$ what $<\quad$ quicker than surrounding talk

<what> slower than surrounding talk

${ }^{\circ}$ what $^{\circ} \quad$ quieter than surrounding talk

WHAT relatively high amplitude

what denotes emphatic stress

(( )) further comments of the transcriber

vet inte talk in Swedish

aforin talk in Persian

lowbia talk in Kurdish

okay beans translation to English from Swedish, Persian or Kurdish

\section{Key to morphologic abbreviations}

1 first person

2 second person

3 third person

DEF definite

EZ ezāfeh (connects two words)

IMP imperative

NEG negative

PL plural

POSS possessive

PRF perfect

PRS present

PROG progressive

PST past 
SG singular

\section{References}

Bani-Shoraka, Helena. 2008. Challenging social hierarchy: Playing with oppositional identities in family talk. Multilingua, 27(1-2). 13-35.

Blommaert, Jan. 2010. The sociolinguistics of globalization. Cambridge: Cambridge University Press.

Blum-Kulka, Shoshana. 1997. Dinner talk: Cultural patterns of sociability and socialization in family discourse. Mahwah, NY: Lawrence Erlbaum.

Cekaite, Asta. 2009. Soliciting teacher attention in an L2 classroom: Embodied actions and affective displays. Applied Linguistics, 30 (1). 26-48.

Cekaite, Asta. 2012. Affective stances in teacher-novice student interactions: Language, embodiment, and willingness to learn in a Swedish primary classroom. Language in Society, 41(5). 641-670.

Chevalier, Sarah. 2013. Caregiver responses to the language mixing of a young trilingual. Multilingua- Journal of Cross-Cultural and Interlanguage Communication, 32 (1). 1-32.

Cromdal, Jakob. 2004. Building bilingual oppositions: Code-switching in children's disputes. Language in Society, 33(1). 33-58.

Duranti, Alessandro, Elinor, Ochs \& Bambi B. Schieffelin (eds.). 2012. Handbook of language socialization. Malden, Mass.: Wiley-Blackwell.

Du Bois, John W. The Stance Triangle. In Englebretson, Robert (ed.). 2007. Stancetaking in Discourse: Subjectivity, Evaluation, Interaction, 139-182. Amsterdam: John Benjamins.

Döpke, Susanne. 1992. One parent, one language: An interactional approach. Amsterdam: John Benjamins.

Evaldsson, Ann-Carita, Cekaite, Asta. 2010. Subverting and reproducing linguistic norms in peer groups. Pragmatics, 20 (4). 587-605. 
Fina, Anna de. 2012. Family interaction and engagement with the heritage language: A case study. Multilingua- Journal of Cross-Cultural and Interlanguage Communication, 31 (4). 349-379.

Fishman, Joshua. A. 1991. Reversing language shift: Theoretical and empirical foundations of assistance to threatened languages. Clevedon: Multilingual Matters.

Fogle, Lyn W. 2012. Second language socialization and learner agency: Adoptive family talk. Clevedon: Multilingual Matters.

Fogle, Lyn W. 2013. Parental ethnotheories and family language policy in transnational adoptive families. Language Policy, 12 (1). 83-102.

Gafaranga, Josef. 2010. Medium request: Talking language shift into being. Language in Society, 32 (2). 241-270.

Goffman, Erving. 1974. Frame analysis: An essay on the organization of experience. Cambridge: Harvard University Press.

Goodwin, Charles. 2000. Pointing and the collaborative construction of meaning in aphasia. Texas Linguistic Forum, (43). 67-76.

Goodwin, Marjorie Harness 1990. He-Said-She-Said: Talk as Social Organization among Black Children. Bloomington: Indiana University Press.

Goodwin, Marjorie Harness, Asta Cekaite \& Charles Goodwin. 2012. Emotion as stance. In Marja Leena Sorjänen \& Anssi Peräkylä (Eds.), Emotion in interaction, 16-63. Oxford: Oxford University Press.

Heath, Christian, Jon Hindmarsh \& Paul Luff. 2010. Video in qualitative research: Analyzing social interaction in everyday life. Chennai: India.

Jefferson, Gail. 1986. Notes on 'latency' in overlap onset. Human Studies, 9 (2-3), 153-183.

King, Kendall. A., \& Lyn Fogle. 2006. Bilingual parenting as good parenting: Parents' perspectives on family language policy for additive bilingualism. International Journal of Bilingual Education and Bilingualism, 9(6). 695-712. 
King, Kendall. A., Natalie Schilling-Estes, Lyn Fogle, Jia Jackie Lou \& Barbara Soukup. (Eds.). 2008. Sustaining linguistic diversity: Endangered and minority languages and language varieties. Washington, DC: Georgetown University Press.

Lanza, Elizabeth. 2004. Language mixing in infant bilingualism: A sociolinguistic perspective. New York: Oxford University Press.

Luykx, Aurolyn. 2005. Children as socializing agents: Family language policy in situations of language shift. Proceedings of the $4^{\text {th }}$ International Symposium on Bilingualism (ISB), 14071414.

Moinian, Farzaneh. 2007. Negotiating identities: Exploring children's perspectives on themselves and their lives. Stockholm: Stockholm Institute of Education Press dissertation.

Ochs, Elinor. 1996. Linguistic resources for socializing humanity. In John J. Gumperz, Stephen C. Levinson (Eds.), Rethinking linguistic relatively, 407-437. New York: Cambridge University Press.

Ochs, Elinor. 1988. Culture and language development: Language acquisition and language socialization in a Samoan village. Cambridge: Cambridge University Press.

Ogiermann, Eva. 2013. On the inclusive and exclusive functions of the 'other' language in family talk. Multilingua- Journal of Cross-Cultural and Interlanguage Communication, 32(4). 463-484.

Paugh, Amy L. 2005. Multilingual play: Children's code-switching, role play, and agency in Dominica, West Indies. Language in Society, 34(1). 63-86.

Palviainen, Åsa \& Sally Boyd. 2013. Unity in discourse, diversity in practice: The one person one language policy in bilingual families. In Schwartz, Mila \& Anna Verschik (Eds.), Successful family language policy: Parents, Children and Educators in Interaction, Multilingual Education 7.

Piller, Ingrid. 2001. Private language planning: The best of both worlds. Estudios de Sociolingüística, 2 (1). 61-80.

Pitton, Liliane Meyer. 2013. From language maintenance to bilingual parenting: Negotiating behavior and language choice at the dinner table in binational-bilingual families. MultilinguaJournal of Cross-Cultural and Interlanguage Communication, 32(4). 507-526. 
Quay, Suzanne. 2008. Dinner conversations with a trilingual two-year-old: Language socialization in a multilingual context. First Language, 28 (1). 5-33.

Rindstedt, Camilla \& Karin Aronsson. 2002. Growing up monolingual in a bilingual community: The Quichua revitalization paradox. Language in Society, 31 (5). 721-742.

Schieffelin, Bambi. B. 1990. The give and take of everyday life: Language socialization of Kaluli children. Cambridge: Cambridge University Press.

Seedhouse, Paul. 2004. The interactional architecture of the language classroom: A conversation analysis perspective. Malden: Blackwell.

Shohamy, Elana. 2006. Language policy: Hidden agendas and new approaches. London: Routledge.

Tuominen, Anne. 1999. Who decides the home language? A look at multilingual families. International Journal of Sociology of Language, (140), 59-76.

Vuchinich, Samuel. 1990. The sequential organization of closing in verbal family conflict. In Grimshaw, Allen D. (Ed.), Conflict talk: Sociolinguistic investigations of arguments in conversations. Britain: Cambridge University Press.

Wei, Li. 1994. Three generations, two languages, one family: Language choice and language shift in a Chinese community in Britain. Clevedon: Multilingual Matters.

Wei, Li (ed.). 2012. Language policy and practice in multilingual, transnational families and beyond. Journal of Multilingual and Multicultural Development, 33 (1). 1-2. 